\title{
Sustainability Problematization and Modeling Opportunities
}

\author{
Eniko Kovacs ${ }^{1,2}$, Maria-Alexandra Hoaghia ${ }^{1}$, Lacrimioara Senila ${ }^{1}{ }^{1}$, \\ Daniela Alexandra Scurtu ${ }^{1}\left(\mathbb{D}\right.$, Diana Elena Dumitras ${ }^{2, *}$ (D) and Cecilia Roman ${ }^{1}$
}

1 Research Institute for Analytical Instrumentation subsidiary, National Institute for Research and Development of Optoelectronics Bucharest INOE 2000, 400293 Cluj-Napoca, Romania; eniko.kovacs@icia.ro (E.K.); alexandra.hoaghia@icia.ro (M.-A.H.); lacri.senila@icia.ro (L.S.); daniela.scurtu@icia.ro (D.A.S.); cici_roman@yahoo.com (C.R.)

2 Faculty of Horticulture, University of Agricultural Sciences and Veterinary Medicine, 400372 Cluj-Napoca, Romania

* Correspondence: ddumitras@usamvcluj.ro

Received: 28 October 2020; Accepted: 30 November 2020; Published: 1 December 2020

\begin{abstract}
A sound theoretical ground is required for sustainability related concepts reconciliation and operationalization. The current study investigates the opportunities to conceive a homogenous sustainability model derived from theoretical ecology, using as a prototype the "organization" concept from the Chemical Organizations Theory (COT). A sustainability problematization and a literature examination try to capture and link some useful perspectives and sustainability connected concepts. Some of the most influential methods and tools are reviewed, in particular among those relating to the triple bottom line framework and to the ecological footprint family, together with concepts close to the core sustainability definition, like resilience and circularity. Theoretical ecology provides candidate goal functions based on self-organization gradients, such as fitness functions and thermodynamic orientors. The COT formalism provides a higher abstraction level and the algorithms for patterns identification in a reactions network. The sustainability problematization reveals the motifs of a possible model of "total ecosystem", which subordinates the anthropic cultural (social-economic) system to the thermodynamic, chemical, biological, and cultural determinisms regulating biological and cultural species of an ecological network.
\end{abstract}

Keywords: ecology; chemical organization theory; self-organization; triple bottom line; ecosystem model

\section{Introduction}

Sustainability is a fuzzy concept depending on the community goals (values), spatial-temporal scale, biophysical internal configuration and external conditions variability, cultural regulation (social-economic behaviors, policies, and standards of rationality), network connectivity and nestedness variability, and proximate and ultimate causal drivers of change. Planetary limits, such as biophysical conditions incompatibility and resources unavailability, can be reached in the dynamic context of unpredicted feedbacks and disproportionate paces. Sustainability strategies consider: Component processes and spatial-temporal patterns; state transitions and evolutionary pathways; pace changes from gradual to sudden, threshold-related shifts. Sustainability is connected to concepts like resilience, adaptive capacity, and vulnerability. Its environmental and cultural (economic, social) change factors are subject to mutual influences (feedbacks, dependencies, and overlaps) and propagate complex causal relationships from local to global scales, requiring adaptive management [1].

Geissdoerfer et al. [2] retrace the evolution of the sustainability representation from Elkington's "three pillars", proposed in 1997 and encompassing people, profit, and planet, to the "triple bottom line" 
(TBL) proposed at the World Summit in 2002, as "the balanced integration of economic performance, social inclusiveness and environmental resilience, to the benefit of current and future generations". Sustainability appears as the union of three distinct goal functions, with their respective optimization criteria: Economic performance (profit), human community development (social inclusiveness), and the ecological resilience (ecosystem functions in far-from-equilibrium states), using various aggregation levels and rather subjective weighting and normalizing methods [3].

The sustainability concept's definitions are not convergent, the coexistence of many different perspectives suggest that the cultural influence strongly subverts both empirical and theoretical approaches. An ambiguous, polysemic, and possibly contradictory sustainability concept is not operational. Salas-Zapata and Ortiz-Muñoz [4] mention that a majority of scholars avoid defining sustainability or study it via focal systems' social and ecological attributes, which generate at least three classes of issues: Construct validity and undecidability of the sustainability models, and confusion in the studied topics. Therefore, developing a sustainability body of knowledge requires semantic and conceptual diachronic studies, from theoretical and operational perspectives. Concepts and definitions are distinct: Definitions are terms pointing to an object, while concepts emerge from a reflection process and are developed gradually, by eliminating uncertainties. Therefore, community usage of the concept is more relevant than definitions and reveals sustainability as: A set of social-ecological action criteria; an anthropogenic perspective on a focal system, converging social and ecological goal functions; a phenomenon occurring in certain social-ecological systems; a methodology of social and ecological variables integration within the anthropic production and consumption systems.

An intellectual construct derived from inconsistent definitions, scope, and views, cannot reconcile policy makers, industry practitioners, civil society, and scholars. For instance, according to a survey realized by Buchholz et al. [5], biomass-based energy production and consumption systems are not obviously sustainable, in spite of the policies and strategies orientation. Moreover, the selected critical indicators of sustainability do not reach consensus, remaining dependent on the cultural horizons of the respondents. The authors conclude that biomass-biofuels-bioenergy supply chains' sustainability assessment should consider the total production cycle starting with biomass production and logistics, up to the energy conversion and allocation, and it should include a holistic systems approach. By analogy with organisms in ecosystems, both the metabolic chains of processes, endogenous (resources processing) and exogenous (trophic interactions), should be considered for the sustainability evaluation. Implicitly, the behavioral aspects of the process-carrying entities should be modeled, due to their causal influence on the social-economic-ecological transactions whose consequences are under evaluation. Thus, it seems that sustainability encloses a contradiction: Although its criteria tend to be represented as goals assigned to the components of the system, the concept makes sense only at a holistic, aggregated level, progressively losing its signification when moving towards an individual level. Semantically, a sub-system (as holon) can be sustainable only if related to its environment (meta-system) or when considered as a meta-system itself, related to its disaggregated components, but not when considered in isolation, as a self-contained, unary structure. Fath [6] considers sustainability as "a function of whole systems, not of parts", related to self-reinforcing, positive feedback strategies, and to an inter-systems coupling which optimizes energy gradients. Thus, sustainability uses mechanisms specific to the complex adaptive systems: Autocatalysis (cascaded facilitation) and self-organization.

In a multi-agent model, sustainability might be defined as an optimization problem regarding the goal functions assigned to the agents. For example, from an ecological perspective, the agent types are species maximizing their fitness, and the sustainability criteria could be defined as fitness currencies. However, such a model misses the holistic dimension of the sustainability orchestration (related to the emergence in complex adaptive systems) by considering only a "flat" representation of atomistic exchanges of flows, maximizing the individual goals of the sub-systems. Finding abstract goal functions and optimization currencies able to collect individual value perceptions and to transform them in a shared perspective, rendering reactive and networkable the initial assemblage of components, 
is a condition for succeeding in formalizing self-organization. It is assumed that a model based only on predation, without reciprocation, predicts the total extinction of populations in the system, after a finite number of iterations (generations of organisms or acts of predation). Additionally, local (individual) chaotic patterns can diffuse at the system level, corrupting stability patterns. Moreover, individual-based models induce a lack of analytic tractability and outcome robustness, due to unpredictable interactions or unobservable variables, requiring heterogeneity reduction through dynamic patterns, or statistical or stochastic models [7].

However, managing the global meta-stability is not a matter of species selection, but a matter of processes selection according to the targeted organizational structure of the system. Species work as concentrators of whole or parts of pathways (process chains) and if one species was able to artificially implement all the necessary and sufficient ecosystem processes, it would also be able to replicate an entire natural ecosystem (as a possible corollary of the Ashby's requisite variety law). Meanwhile, the species diversity conservation, requiring spontaneous organization and a fully shared and distributed control over the Biosphere, remains the only effective strategy of managing natural ecosystems, and this is feasible only by segregating anthropic processes within local, isolated, autonomous cultural habitats, such as urban and industrial ecosystems, whose sustainability is driven by a cultural determinism and depends on their capacity to limit inputs from the ecosystems. Guarini et al. [8] suggest that an optimal ecological compartmentalization should be implemented by the urban planning models. For this purpose, they recommend the Integrative Ecosystem Assessment Frameworks, which consider ecosystem goals by combining natural and socioeconomic factors, under the ecosystem services paradigm. Therefore, the authors propose the "Total Ecosystem Value", a homogenous, technical evaluative methodology. Lin and Sutherland [9] study community dynamics in food webs, at the landscape level and for different types of species interactions, concluding that the network compartmentalization's patterns of influence on the community stability or resilience depend on the inter-compartment connectivity and can result in two-way feedbacks (inter-compartments perturbations generate circular buffering effects). Under optimal system control, spatial patterns emerge: Economic activities (e.g., industries, trading places, or residential buildings) tend to concentrate on particular sites in urban and rural areas [7]. Assuming that such an urban and industrial concentration strategy is on the way, the existence of socio-ecological systems (SES) (e.g., due to agriculture or to extractive, fishing, hydro-energy, bioenergy, and timber processing industries) remains, however, extremely problematic for the global sustainability, and restraining their noxious processes passes by constraining their economic goals through social goals and the social goals through ecological goals. Implicitly, defining the goals architecture required for a sustainable SES should consider specific fitness levels and fitness optimization currencies, in the context of species interactions.

Therefore, in SES, the commercial value (from a unilateral consumer species perspective) is not an appropriate reference for building sustainability from the interactions in presence. Flattening the currencies hierarchy to the level of a subjectively chosen currency polarizes the network connections, neutralizing the self-organizing capacity of the ecosystem. The currencies hierarchy should be based on gradients of generality, according to an abstract ladder of causations, with the thermodynamic determinism on top, descending through the chemical, biological, and eventually to the cultural determinism at the basis of the causal architecture. It is remarkable that generality, in such a values hierarchy, is inversely correlated with the structural complexity gradient, which evolves from free energy (general, unconstrained flows), via dissipative structures (matter, a constrained and complex energy storage) towards structural information (material-energy semantic units specifying the network pathways). Cultural currencies (values) are specific, relatively local semantic constraints over a cultural community, with a limited influence on the self-organizing capability of its meta-systems, but strongly influencing the local network. Anthropic cultural values (if considered as cultural fitness currencies), like money, have a limited transformational impact on the ecosystem, due to their lack of generality, but they are strongly generative of amplifying indirect effects. All intra-specific currencies increase the phenotypic fitness or the intra-species community benefits, due to mutualism or reciprocation, 
but they are of a limited importance to the ecosystem or to an inter-species assemblage. Conversely, any specific biotic resource is made of embodied generic nutrients, such as basic organic matter and minerals, which are more likely to be functional as general currency across the ecosphere. Basic needs are a generic language between species. Fath [10] shows that the currency in ecological networks can be biomass (grams of carbon), energy, nutrients or water (per space and time), but also a combination of $C$, $\mathrm{N}$, or $\mathrm{P}$, since ecological network models should be able to represent ecological interactions, including structural cycling and indirectness. Network modeling phases are: Major species or functional groups identification, network currency selection (for capturing the throughflow value), complete flow interactions identification, storage measuring for each compartment, inter-compartments input/output /throughflows measuring, and flow/storage balancing algorithms determination.

As a corollary of the maximum empower principle, which predicts that systems maximizing power will prevail [11], conservative unary goals (individual fitness maximization) oppose the plurality persistence and evolvability (optimal efficiency by self-organized development), therefore inter-components tradeoffs and arrangements necessarily occur in all types of complex adaptive systems, such as ecosystems and human society. The TBL is a tentative implementation of such a compromise, by juxtaposing three overlapping systems, considered, however, of distinct types. Conversely, sustainability is a homogenous property derived from the coherence of a system and referring essentially not to the components themselves, but to their global interactions (transactions and relations). Therefore, sustainability is intolerant to a conceptual fragmentation. Milne and Gray [12] consider that TBL "in all its forms is a deeply problematic concept", being "a change-but-no-change rhetoric of sustainability" and "ill-developed and incomplete notion". By analogy with a relational database, the triple bottom line is a query using the "union all" instruction, returning disparate datasets displayed together, creating the illusion of unique records. The problem is the model of the database relational scheme: Tables should be linked based on a sound conceptual model, which would enable a query on the focal system's sustainability to return complete and unique records, carrying consistent information and linking data from the various fields through causal relationships. If the database was the immediate reality, an abstract model would allow us to extract data from, and to generate data into, the tables of the sustainability information system, according to metadata and patterns shared by the three pillars (ecological, social, and economic). This is due to the cascaded inheritance of class properties (e.g., patterns defined by orientors), along a hierarchy of abstract classes ("ancestors"), by their ultimate, concrete instances (objects specific to each domain). An example is the concept of a complex adaptive system (CAS), an abstract class implementing lower level classes for the types of ecosystem, social system, and economic system, which are, in turn, classes of various systems: Forests, lakes, oceans (ecosystems), ant colonies, human societies (social systems), capitalist or socialist systems (economic systems), and all these lowest level classes implementing concrete occurrences (objects).

Different values and principles define sustainability frameworks, such as: Ecological, focusing on thresholds; steady state or balance of nature; carrying capacity; interdependence between ecological processes; and a global biophysical system embedding the socio-economic sub-system [13]. The commonly applied methodologies for sustainability assessments are: The reductionist approach, combining the results of multiple models for the three pillars; the holistic approach, where the emergent properties of the socio-ecological system prevail; the combined approach between holistic evaluation and specific or local reductionist models and methods. Waring et al. [14] explain that most of the systems analytical frameworks build on models of anthropic-environmental systems as CAS, such as coupled human and natural systems (CHANs) and SESs, including concepts like resilience and vulnerability in order to characterize the internal causal structure (determining the system states) and the adaptive capacity to alternative system states. Current multilevel frameworks such as polycentric approach, panarchy, and multilevel governance do not contain general mechanisms of causation across levels of organization, or guidance for designing policy in multilevel contexts. Therefore, sustainability theory should include a causal model of endogenous cultural processes explaining the emergence and persistence of social-ecological states and the multilevel interactions. 
The current study builds on the systemic perspective on the sustainability concept and benefits in particular from the vision offered by Fath [15], who defines sustainability as a holistic property of a system denoting its capacity to maintain processes and structures configuration, supporting their persistence. The sustaining functions emerge naturally from the structures, conveying the flows generated by the gradients through coupled, recursive actions and according to the gradient propensity. Thus, the processes and structures mutually reinforce in autocatalytic chains (e.g., producer-consumer loops, biogeochemical cycles) renewing the gradients. Sustainable ecosystems are determined by holistic (system scale), self-supporting, consolidating, endogenous, and exogenous life-sustaining interactions of isolated organisms.

Alvesson and Sandberg [16] elaborate on the problematization process, considering it as being rather iterative than linear, unrestricted to an analytical procedure, less exhaustive (selecting only specific literature) than the gap-spotting research, but also less critical and limited to reproducing the crucial assumptions of the reviewed studies. Key texts might be examined by focusing on identifying and possibly challenging their underlying assumptions. Problematization opportunities are evaluated through detailed or iterative in-depth references to major studies. Challenging the existing assumptions may consist in dissociating from them and formulating an alternative assumption ground for theory development. Problematization includes constructive and deconstructive perspectives as a process of critical thinking regarding issues, involving deconstruction of common knowledge taken for granted and construction of new viewpoints [17].

Starting with a problematization of the sustainability concept (Figure 1), the present work investigates the opportunities to conceive a different sustainability model, based on a deeper ecological conceptualization and on a reference concept, the "organization" (from the Chemical Organizations Theory (COT)), as theoretical prototype of a sustainable system. The study was built on the above mentioned problematization methodology. A non-exhaustive literature examination tries to capture some useful perspectives on the sustainability and its connected concepts converging towards a model of ecological inspiration, the "total ecosystem model".

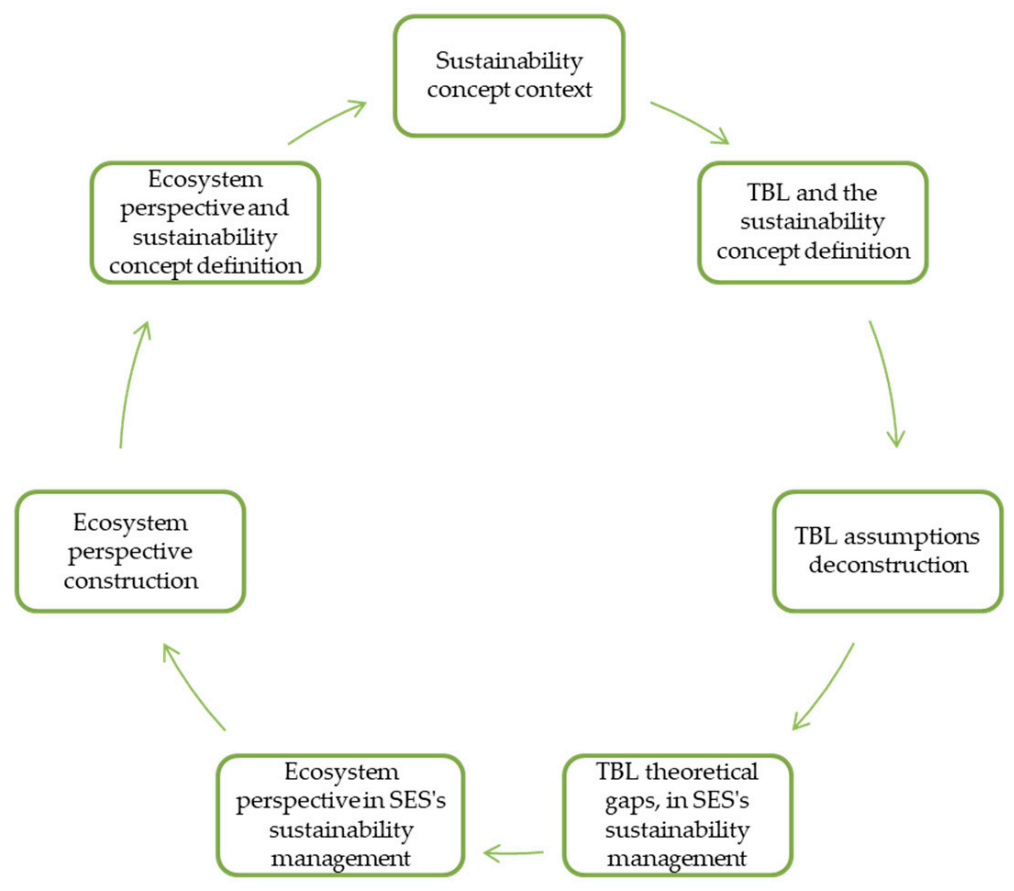

Figure 1. Sustainability concept definition problematization.

The present study is structured as follows: Section 2 introduces the theoretical background, with regard to the challenged key assumptions from selected applied methodology and modeling approaches of sustainability and its mainstream ecological conceptualization, in particular the industrial 
ecology, with some remarkable modeling advances. Section 3 provides the foreground for the alternative assumptions, consisting of a formal basis for a theoretical sustainable system and a brief presentation of three sustainability-relevant classes of qualitative orientors corresponding to the fundamental extremal principles of the systems ecology. Section 4 presents the alternative assumptions as a proposal of an extended ecosystem model for SESs sustainability management, which immerses the anthropic cultural system in an ecosystem conceptual model. Ultimately, Section 5 presents the conclusions.

\section{Theoretical Background}

\subsection{Conventional Sustainability Approaches}

Sustainability explores the multi-scale interactions between the sub-systems of a meta-system (as ultimate aggregation level), at nested or equal organizational levels. In most cases, the studied systems are built around human communities, from global to local, such as countries, cities, or social-economic entities, with predominantly cultural underlying relationships, but also regulated by other determinisms, such as bio-ecological, chemical, and thermodynamic causations. Van de Kerk et al. [18] propose the Sustainable Society Index (SSI), aggregated at the country level, designed for screening the environmental and economic societal issues. It measures the distance to full sustainability for each indicator corresponding to the resource depletion, environmental-ecological aspects, and quality of life categories.

Limiting factors and tipping points are often invoked by the proposed sustainability models, stressing on the importance of resource flows and buffers regulation throughout the system. McElroy et al. [19] propose the Context Based Sustainability (CBS) and Multi-Capital Scorecard (MCS) instruments for an economic entity's sustainability performance monitoring, based on the principle of preserving the global vital capitals within the carrying capacity limits, by considering ecological and anthropogenic (human and intellectual, social, technological, and economic) capitals. The MCS tries to circumscribe the system by referring to the vital capitals (financial capital included) stocks and flows, to the entity impacts on capitals and on their calculation, and to the entity's capital-dependent stakeholders (e.g., individuals, communities, or entities). Bossel [20] adopts a functional perspective on human society development (derived from the "livelihoods framework") whose component systems are partitioned by "essential capital" types: Human, natural, financial, social, and physical, with an arguable extension, the "organizational capital". The autonomy of these component systems depends on their inner connectivity level. The author suggests that indicators for sustainable development should represent the "essential capital" systems according to a spatial scale gradient and should ultimately aggregate into three subsystems: The human (social) system, the support system (physical and financial-economic infrastructures), and the natural system (natural resources and environmental systems), thereby converging with the TBL approach.

Most of the sustainability approaches suggest tradeoffs between the focal system and its environment or between competing consumers in a system, as a regulating mechanism seeking for quantitative balance and pace synchronization between natural resources generation or cycling processes and consumption processes. From this perspective, in SES, the economic value and growth, as understood by the current dominant cultural constructs, appear rather as inhibitors than as catalysts of the sustainable processes. According to Wackernagel et al. [21], the minimal condition required for sustainability is to live within the limits of the biosphere's regenerative capacity. The "ecological overshoot" global accounting framework, based on the ratio of current demand per bio-productive capacity, delivers data on the anthropic environmental expansion and builds on the "ecological footprint". Wackernagel et al. [22] explain the ecological footprint concept, which measures the impacts of the production, consumption, and waste loads on the planetary bio-capacity, in terms of annual biomass primary production used for anthropic activities. Land and sea area types are weighted with an "equivalence" factor reflecting their maximum bio-productivities estimated through a normalized "agricultural suitability index" (SI). The aggregation result signifies the "biologically productive space 
per capita" for a given population category. The carrying capacity of an ecosystem is a function of its resources renewability and consumption rates. From a reversed perspective, the "ecological yield" is the growth rate of the harvestable population as a fraction of the bio-productivity (e.g., in forest ecosystems, the harvested wood per patch and period), applicable to any renewable resource. The economic value correlates to the ecological yield: Paybacks increase with the resource harvesting intensity, which explains the overestimation of the biomass renewability capacity. Krotscheck et al. [23] develop the Sustainable Process Index (SPI) in order to compare the aggregated environmental stressors along the full production life cycle (from mining to disposal). The SPI matches technological against natural mass/energy flows according to the sustainability principles: Anthropogenic flows should not destabilize the biogeochemical cycles and should not exceed the local biogenesis and assimilation capacities. The SPI is the per capita ratio of two types of areas: One encapsulates the whole industrial process (production system's life cycle) and the other the natural cycling process. The maximal natural rates of exchange, absorption, and renewability discriminate between Earth surface compartments. The SPI of a macro-process is the sub-processes' aggregated value of the partial footprints accounting for resources consumption (materials and infrastructure, processing energy, manpower) and waste/emissions inventories, in a sustainable scenario. On the basis of strong sustainability, the SPI provides a method to quantify human behaviors, manufacturing practices, goods, facilities, and environments [24].

Bossel [20] elaborates on systems viability and sustainability under the environmental constraints exerted on their self-organizing and co-evolutionary development, including in its scope both biological species evolution in ecosystems and cultural species development (technical and organizational) in societies. These constraints determine elementary orientation criteria in self-organizing systems (e.g., organisms, community), called basic orientors. Among the latter, "existence" is close to the concept of ecological niche and refers to the availability of the essential resources (information, energy, and material inputs) and to the compatibility between system's states and environmental states. The other orientors refer to the system's self-regulation through the activation of feedback chains under constraints, in order to dampen various types of perturbations: "Effectiveness" denotes exerting control on the environment (e.g., niche construction) in response to low concentrations of resources; "freedom of action" denotes generating appropriate active behaviors in response to the environmental variety (diversity); "security" denotes accessing defense mechanisms in response to the environmental variability (i.e., fluctuating and unpredictable conditions); "adaptability" denotes optimizing reactions through learning and self-organizing processes in response to the environmental change; "coexistence" denotes generating appropriate reactive behaviors in response to the behaviors of environmental systems. Systems' orientation sets the first priority on viability (basic orientors) and the second on performance (individual orientors). Once the basic orientors have been satisfied, differences in the perception of the individual orientors' importance determine the behavioral choices of organisms and associated systems (i.e., communities, cultural groups), in order to maximize performance (fitness) and provide a competitive advantage (survival of the fittest). Provided the viability conditions, sustainable development can follow multiple optimization pathways (but the solution for sustainable dynamics is not trivial). System dynamics (processes regulation and states selection) operates through certain functional groups of processes: Stimulus-response, feedback control, adaptation, self-organization, evolution, and integrity maintaining, at different time scales and by modifying from simple, exogenous, quantitative parameters to complex, endogenous, quantitative and qualitative variables, referring to the structure, goals, and orientors [25]. Integrity, at the top of the system functions, is constrained by functional persistence (resilience or vital processes recovery) and structural persistence (resource-consumer processes circularity or stock-flow balancing).

\subsection{The Industrial Ecology Perspective}

Industrial ecology (IE) deploys noticeable methodological efforts for transferring operational concepts from the ecological systems towards the economic and social domains. Many of its concepts 
were adapted to the socio-economic systems modeling, in particular to the impacts and sustainability assessment of industrial and urban systems. A sustainability concept based on the TBL remains cardinal for the whole potential of the IE concepts, methods, models, tools, and frameworks. IE provides a sustainability analysis platform to the production systems, encompassing concepts like: "Industrial metabolism", "closed industrial ecosystem", "technological food webs", "industrial symbiosis", etc., and frameworks like the life-cycle assessment and net energy analysis, facilitating comparative complex studies, as shown by Ehrenfeld [26]. The industrial ecology, originating from an analogy with ecosystems' cyclical use of resource flows, is defined by Lifset et al. [27] as a cluster of concepts and tools which examines the sustainability of materials and energy flows production and consumption. IE emphasizes the importance of a systems perspective in environmental analysis, management, and policy, and includes tools such as life cycle assessment (LCA), material flow analysis (MFA), input-output analysis, and design for environment (DfE), based on the central concepts of: Industrial symbiosis, eco-efficiency, dematerialization, and urban/industrial metabolism. Pauliuk and Hertwich [28] highlight that the systems approach is "the widely accepted epistemological basis of environmental literacy". The most usual IE models and frameworks are: MFA, substance flow analysis, physical supply and use tables (SUT, i.e., Leontief's input/output matrix used in computable general equilibrium models, CGE), LCA, environmentally extended multi-regional input/output analysis (EE-MR-IO), dynamic scenario-based hybrid models, and combinations of systems dynamics with agent-based models. They use quite similar concepts, but various criteria for determining the system boundary, unit process, physical or monetary perspectives, spatial coverage and temporal scale, external parameters, and society-nature interactions. The concept of "metabolism" (qualified by the authors as "the totality of the chemical reactions and physical changes that occur in living organisms") was transposed from biology to the social context as "socio-economic metabolism" (SEM) and used in material and energy flows accounting.

As exposed by Ekener et al. [29], the conventional life cycle sustainability assessment (LCSA) outputs a composite index and a combination of category indicators. In LCSA, sustainability perspectives remain disparate, lacking the final integration of the dimensions. Multi-criteria decision analysis (MCDA) methodologies can combine environmental life cycle assessment (ELCA), social LCA (SLCA), life cycle costing (LCC), and other approaches, by ranking conflicting objectives and decision alternatives, based on performance and preference criteria. An alternate solution would consist of multiplexing the TBL dimensions in a unique model of a higher abstraction level, generating homogenous goal functions and optimization currencies. Millward-Hopkins et al. [30] observe the lack of a dynamic approach (temporal projections) of the conventional IE frameworks and their focus on the processes downstream, while prevention strategies are missing. Additionally, LCSA applications are not sufficiently analytical and lack holistic vision (e.g., at the industrial sector level). In conventional LCSA, aggregation is problematic, causal dependencies between interacting systems are not thoroughly investigated, and indicators are inappropriate. Consequently, the authors propose a modeling approach for value retention assessments (applied to the renewable resources from waste, RRfW), which integrates the environmental, social, economic, and technical perspectives with MFA and LCA methodologies, within a one-dimensional, consistent and computable model. Their "Complex-Value Optimization for Resource Recovery" (C-VORR) multiplex-model converges the concepts into a unique construct, instead of mixing inconsistent multiple outputs from parallel models in a unique numerical result. The multiplexing method is based on the conversion of the domain-specific metrics to an abstract typology, in favor of a consistent, trans-domain analysis. The material flows' transfer coefficients reflect the value life cycle and are computed following a hierarchical causal path. The technical value of an outflowing substance, determined by its concentration, decides if it will be recovered or disposed. Their model is integrated to a consequential LCA (CLCA) in order to represent the complex foreground-background systems dynamics as depending on (non-market) drivers, whose distributional effects exclude a direct allocation. The model increases the LCA models' abstraction level and identifies a keystone rendering their "fitness currency" concept operational. 
Schiller et al. [31] propose to deploy the social determinism into the economic systems via "social-material multiplexing networks". The model is not based on a system extension method, but on superimposing social determinism and economic organization, thus increasing networks connectance and systems coherence. The resulting network will be closer to the complex adaptive system model, with self-organizing behaviors, and thus will be even more susceptible to inherit from ecosystem models. Authors claim the necessity of extending the IE focus from the functional metabolism (physical layer) to the indirect but decisive influence of the social interactions (i.e., contracts, relationships, contextual parameters) between the entities which convey the flows (knowledge, payments, materials, technology). Consequently, they elaborate on a conceptual representation of the social system, based on multiplexing networks of multi-layered physical and social connections between the social-economic entities, by simultaneously combining several relationship types, such as: Material-energy flows exchange, financial transactions, information communication, and social arrangements. The dissipative physical flows' immediate interactions have remote causal projections in time and space, mediated by social relationships (i.e., contracts, knowledge), thus generating anthropogenic flows. The co-evolutionary mechanisms of the socially interacting entities within the production systems determine the network connections typology (i.e., industrial symbiosis, competition, corporate responsibility, technological and organizational alliances). Authors suggest a combination of Social-Material Network Analyses with the LCA framework, applicable to the industrial symbiosis' impacts evaluation, but also for investigating the eco-industrial paths stability and resilience under shocks, relaying on their bio-physical resource base. An ecological conceptualization of the production systems is complex, when applied to large social network structures, even if the markets are well modeled. The authors insist on the role of the social interactions formalism in verifying the economic models: Self-organizing and scale-free network models based on preferential attachment do not explain the co-evolutionary social-economic mechanisms, leaving a theoretical gap solved by network models of "symbiotic reverse flows" (proximity feedback loops) and "socially nested production structures" (inter-scales feedback loops). These models cover conceptual and formal lacks related to the cumulative upward causations' propagation, which drive the socio-environmental metabolism within the self-organizing production systems.

\section{Methods}

Social and ecological systems are complex adaptive systems, comprising individual agents (assigned to evolutionary processes) which seek for fitness maximization, compete for limited resources, and can promote antagonistic or cooperation group dynamics, endorsing functional roles within the system. Collective behaviors can scale-up the effects of local actions, generating feedbacks, possibly nonlinear, potentially causing regime shifts. In particular, the organizational complexity can cause collapse by regulating without considering the system components' feedbacks throughout the network [7].

Pattern [32] elaborates on the concept and theory of ecosystems, which are dissipative structures selecting far-from-equilibrium states and resulting from organisms' environments (niches) mapping to their interactions web (complex pathways). Direct and indirect linkages partition the multidimensional space of the niches. Relations (indirect interactions) are consequences of transactions (direct exchange of energy, matter, information). A holistic determinism, due to relations proliferation, homogenizes the network by equalizing the flows and amplifying the inputs, and generates the network synergism. Ecosystems are complex adaptive systems elaborating life strategies (species) and opportunities (niches) by testing models, but also cybernetic systems deploying a continuous "control field" (homogenously distributed over the coevolving sub-systems) of developmental, organizational, and evolutionary gradients (determining the system's "orientors"). The completeness of ecosystem's network involves a transitive closure between components, whose overall connection is reached by a spanning cycle (e.g., biogeochemical cycling is one of its natural instances). Organisms individually maximize transactions in ecological networks, but ecosystems holistically maximize relations between organisms, 
by self-organizing and cycling (optimizing energy flows distribution and relations dominance). For instance, iterated nutrients cycling and mineralization enforce the indirect effect throughout the network. The ratio indirect to direct effect is a measure of the network complexity, in terms of pathways density [33].

Fath [6] defines ecosystems as energy networks using available energy to create complex, adaptive, and self-organizing structures, and to maintain dynamic regimes far from thermodynamic equilibrium. Ecological goal functions measure the dynamic orientation and the organizational and dynamical patterns, being derived from thermodynamics, information theory, and network analysis, and assessing various types of complex adaptive systems (such as ecosystems, financial systems, and urban metabolism). Thermodynamic principles (in particular the maximization of work energy capacity, the maximum power principle, and the dissipative structures) are used for measuring the level of complexity. Ecosystems succession implements a critical duality, construction and dissipation, since structures degrade the energy gradient and evolve towards more complex structures, with higher dissipative ability, while the organization of the structures increases their complexification. This dynamic follows driving extremal principles, high level orientors, and is measured through goal functions (lower level orientors) including: Network configuration (e.g., mutualistic relations), energy through flow, exergy storage, energy dissipation (exergy degradation), and specific entropy. Fath [15] proposes two necessary and sufficient ecological high-level constraints, defining the sustainability goal functions: (1) A system requires input access (energy-matter flows, such as solar radiation, global carbon cycle, rate of nutrient cycling, rate of hydrological cycle) and output assimilation structures (constrained by the rate of decomposition, the rate of entropic materials accumulation, and the synergistic couplings for their reuse). Its coupled environmental sink-system must be at a lower gradient than the entropy-rejecting source-system. (2) The continual renewal of the configurations and the persistence of the processes derived from the flow gradients conveyed by the ecosystem (as complex adaptive systems) are realized by means of autocatalysis and self-organization. This self-organization function in far-from-equilibrium states prevents the entropic drift toward disorder. In both object-oriented and process-oriented perspectives, recursion (multi-scale and multi-level feedbacks) and system compartments coupling are central, which is reflected in the ecological spanning cycles.

The necessary and sufficient sustainability constraints, input circulation/output cycling, and the self-organized autocatalytic/auto-inhibitory flow gradients, can be retained for characterizing a sustainable organizational configuration of the system, as a theoretical reference system, being reflected by two qualitative network orientors: Circularity and resilience, together with the thermodynamic orientors defining the quality of the energy throughput. The effectiveness of ecological networks is due to their degree of functionalization (specialization and connectance), determining patterns of the organization functions, described by lower-level qualitative orientors: Diversity, redundancy, modularity, and adaptability (also quantifiable through indicators) [15]. Sustainability is a property of configuration of the system networks and interactions, and copes with the system's outer boundary and inner autocatalytic (gradient-building) self-organizing processes, therefore a reactions network formalism, such as the COT seems adequate for the sustainability theoretical representation as "organization" and for operating with abstractions of ecosystem processes networks.

Representing the SESs' sub-systems as components of a unique ecosystem reflects the producer-consumer (or resource-consumer) natural duality of the processes (concentrated in entities like organisms, populations, communities, or cultural-social-economic entities), either natural or sourced from the anthropic sub-systems (entirely definable within a model of an extended ecosystem). A significant advantage is the possibility to represent thermodynamic, chemical, biological, and cultural causal relationships and goal functions throughout a homogenous processes network. Alberti et al. [34] demonstrate that integrating humans into ecology is crucial for computing the sustainability thresholds and balancing anthropic and natural processes in urban ecosystems. They assume that: (1) Both biophysical and cultural agents control the ecosystem functions, (2) their patterns of development influence the ecosystem dynamics, generating effects on ecological resilience, and (3) in both biological 
and social organization, network causal relations can alter ecosystems emergence. Consequently, it seems adequate to investigate the socioeconomic and biophysical variables effects on the ecosystems processes' distribution and resilience, and on the driven energy and material fluxes, at different scales. The resilience, as change response capacity, is determined by spatial-temporal patterns of the biological and cultural diversity and of the populations and processes interactions, according to the ecosystem organizational gradient.

The above summarized theoretical points will be developed in the following subsections.

\subsection{Formal Basis for a Theoretical Sustainable System}

The concept of organization, from the Chemical Organization's Theory, offers an abstract and inheritable model of sustainability. As a network of interacting processes (reactions), with properties of organizational closure and self-maintenance engendering autonomy and persistence, organizations are the ideal sustainable systems. Organizational closure limits a system's exchange with the environment and implicitly its dependence on external resources and its influence on the environmental mechanisms. Autonomy can be increased at the group level by aggregation of sub-systems until their common "organization" status is reached; for instance, organisms assemblages evolve towards self-organizing swarms. Heyligen et al. [35] suggest COT as a simple and intuitive formalism for self-organizing systems modeling, based on generic resources (potentially representing a variety of concrete entities) and reactions that assign combinations of resources to other combinations, in a modular way. Possible applications concern ecological, economic, social, and technological systems interactions. Reaction networks are computable models operating with flows of resources, using intrinsically dynamic concepts (generic reactions, which can be ecological processes, economic transactions, or social interactions) instead of static nodes (entities). Such networks of production and consumption (e.g., organisms, ecosystems, societies) spontaneously tend to invariant organizational patterns (the "organizations"). Among the concrete COT applications, the authors mention the resilience evaluation in ecosystems or social systems, the formalization of sustainable development, and the construction of the self-organization in SES. Self-sustaining systems (e.g., organisms and communities), based on self-organization and autopoiesis, permanently control and adjust features like: Feedbacks (regulating concentrations and kinetic rates of the flows and buffers of resources), resilience (linking latitude, resistance, and precariousness of the current basin of attraction), evolvability (enabling minimal shifts in response to disturbances), and degeneracy of pathways (linking evolvability, robustness, and complexity). In summary, sustainability relays primarily on: Circularity, resilience, evolvability, and redundancy.

Veloz and Razeto-Barry [36] explain that reaction networks can represent ecological interactions and COT, which can be used as modeling language for reaction networks, is compatible with the ecological concepts and formalisms, due to its abstraction level. In reaction networks, a set of interactions of transformational nature (reactions) is assigned to a set of entities of any nature (physical, biological, social, economic, etc.). Organizations are classes which can be instantiated as sustainable systems. In ecological systems' reaction networks (e.g., food webs), a large number of transformations between species occur (e.g., biomass conversions), rendering dynamic models hardly computable. As an alternative model, COT proposes the dynamic landscape based on a hierarchy of organizations, which are almost independently co-existing subsystems [37]. Heyligen et al. [35] explain that self-organization patterns result from emergence and interactions in complex adaptive systems. COT models are qualitative, accounting for the resources and reactions active in a network (stoichiometry), and quantitative, related to the reaction rates (fluctuating resources concentrations and reaction durations). A simplified model, based on qualitative algebraic properties abstracting the quantitative dependencies between concentrations, can be used for discovering self-sustaining and resilient combinations of reactions and resources (e.g., ecosystem species, active genes of regulatory networks). An organization is by definition self-sustaining, which makes it a theoretical reference model for sustainable systems: It can indefinitely maintain itself, either by inner recycling or through dependable inputs (under renewability constraints), 
without exhausting its resources and thus depriving its essential processes. In order to generate emergent and self-sustaining systems, organizations dispose of evolutionary processes: They permanently recreate their lower-order components (i.e., autopoiesis and self-referencing) and can participate in the creation of higher-order organizations (meta-system transition).

Matsumaru et al. [38] elaborate on the patterns extraction in dynamics modeling, using COT. An organization abstracts the distribution of the molecular species, being an algebraically closed set of entities, able to self-maintain its stoichiometry. A system state, in reaction networks, is determined by its molecular species. Movements between sets of species qualitatively describe the system's dynamics, reducing its model dimensionality, based on the identification of the patterns corresponding to the organizational structure of the reaction network. Closure (formalized by the algebraic operation of transitive closure) is verified when reaction rules cannot produce molecular species which are not included into the set. A self-maintaining set is self-sufficient (self-sustaining), using only its own reactions to reproduce its molecules. With COT, a reaction network can be broken down into a hierarchy of self-maintaining sub-networks (organizations), according to their stoichiometry, in order to analyze its emergent dynamical behavior. Changing the inputs has repercussions for the organizational structure of the system. Additionally, a high number of extensively interacting components determine a chaotic global behavior. By abstracting concrete interaction processes through reaction rules, COT can predict potential behavioral patterns characterizing the dynamics of the abstract structure of any type of system (not only chemical reactions networks).

Heyligen et al. [35] define sustainability as the dynamic regime of a self-maintaining system without external interference and resilience as the dynamic regime of a system which maintains essential organization under external shocks. In organizations, the introduction or the removal of reactive species represent disturbances which will be compensated in order to maintain a viable configuration. Organizations exert control through buffering crucial resources (overproduction due to positive feedbacks) or by adjusting resources concentrations (through negative feedbacks) during consumption and production cycles. In kinetics, reaction rates usually correlate with concentrations: Resources consumption generates a negative feedback, slowing the process rate (e.g., Lotka-Volterra predation models). Feedforward is another control method, consisting in neutralizing perturbations in order to prevent their consequences on vital resources, but the compensatory processes are potentials activated only in the presence of the perturbation or regulated by catalysts. Authors consider that COT can be used to evaluate the degree to which reaction networks, such as ecosystems or socio-economic systems, are self-maintaining. The self-maintenance characterizes the system capacity to preserve its integrity under closure constraints, which means that the initial set of entities and processes available within the system boundaries (and defining its identity) remains unaltered over its lifespan, in spite of concentration and flow rate fluctuations. A self-maintained system disposes of processes (relating to the resilience, circularity, redundancy, and evolvability properties) which restore or replace the lost reactive species, preventing the suppression of their assigned functions and the consequent feedback chains propagation throughout the network (e.g., mass extinctions or invasions following a predator's extinction). Persistent systems without external constraints contain combinations of autocatalytic and auto-inhibitory chains of reactions, tending to form self-constrained cycles. These maintain the system's molecular balance (e.g., minimal diversity and redundancy) by controlling its internal stoichiometry and reaction rates, as well as its exchanges with the environment. A circular economy (CE) regulates stoichiometry, reaction rates and distribution of the resource species, which are essential to the organization's persistence. An organization is sustainable, being a persistent and autonomous network of processes (reactions). It results that circularity is a pre-condition of the sustainability. A system cannot be sustainable without consumption-production couples of processes, implementing the circularity. A system's persistence (and implicitly its sustainability) also depends on its resilience, defined as the capacity to maintain vital functions (processes) while visiting far-from-equilibrium states (e.g., under shocks or by referencing external components). Resilience relies on the ability to maintain sufficient buffers of reactive resources and functional redundancy (active backup copies 
of processes, obtained by autopoietic mechanisms of replication and referencing) in order to avoid suppression of vital functions (reaction chains). These properties can also be formalized based on the reaction networks' patterns, in order to compute sustainable systems from abstract reactions and molecular species.

\subsection{Thermodynamic Sustainability Orientors}

Jorgensen and Nielsen [33] show that ecosystems' evolutionary trends are constrained by thermodynamic orientors, quantifiable via goal functions (e.g., emergy, exergy, structural exergy, ascendency, buffer capacities). Among the goal functions, emergy and exergy concepts enclose energy quality factors. Exergy accounts for the system's kinetic energy (work, reactivity potential, and heat) assimilation capacity and measures the capacity to move away from the thermodynamic equilibrium state using the free energy and structural information embodied in its biomass. Its quality factor consists of the effectiveness of biomass synthesizing, flowing and structuring technologies (functional traits), reflecting the evolutionary status. Emergy accounts for the recursively embodied energy along a biomass conversion path. It is calculated by substitution of the recursive series, corresponding to each resource used at each unit process step, with factors corresponding to pre-calculated solar energy costs per embodied energy source. Costs are incurred while producing a unit of energy in the considered organism. At the ecosystem level, emergy reflects the environmental costs at different trophic levels. The emergy quality factor consists of the effectiveness of the consumption technologies (the functional traits used for recycling or assimilating, embodying, and buffering existing biomass). Emergy and exergy are well correlated and can be normalized based on solar energy equivalents [39].

Emergy captures the value of the energy and material flows across the biosphere, explain Brown and Ulgiati [40], enabling comparisons between ecosystems, at various organizational levels and at different spatial-temporal scales. Natural cycling supports the ecosystems vitality and adaptive capacity, by alternating regimes of structural refining through higher quality energy flows and of matter dispersal through lower quality energy flows. SESs' economic processes extract energy primarily from storages, in order to power their positive feedbacks (growth of physical and informational structures). Ideally, they should also generate negative feedbacks to reduce the resources demand, in particular regarding stocks with slow turnover (minerals and fossil fuels) or fast turnover (ground water and vegetation), which currently can be depleted even at a human generation spatial-temporal scale. Sunlight, tidal momentum, and deep earth heat are the only truly renewable energies. Understanding biosphere requires more than quantitative thermodynamic variables: Complex adaptive systems' processes use biophysical structures potential at a higher technical level, whose value is not captured by the market prices. Emergy quantifies value from the donor perspective, accounting for the total solar energy invested over time by the natural system, through all channels, to create the resource. The Emergy Sustainability Index synthesizes the environmental load, renewability, and efficiency, and is based on a ratio of the emergy yield ratio (EYR, the total emergy consumed per unit of emergy invested) against the environmental loading ratio (ELR, the total nonrenewable and imported emergy released per unit of local renewable resource).

Bastianoni [41] defines the exergy-emergy ratio as a metric for the ecosystem's efficiency in self-organizing and in increasing its complexity levels, along its life cycle. In this context, exergy refers to the energy of self-regulated biogeochemical cycles, while emergy refers to the system complexity expressed by the total solar energy embodied in its natural components (directly or indirectly, at various scales and levels). In engineered systems, exergy is derived from the constraints of the 2nd law of thermodynamics, as the materials' energetic quality degradation during the dissipative conversion processes [42]. Consequently, multilevel material cycles with a complete renewability of the exergy cannot be designed, but exergy loss can be limited (entropy production can be minimized). Gulotta et al. [43] propose extensions of the Cumulative Exergy Demand (CExD), a concept introduced for tracking destroyed exergy through LCA comparisons of technology systems. CExD is the sum of exergy of all resources (including fuels and chemical potential) required to provide a process or product. 
System efficiency is the ratio of the exergy of its outputs, the Useful Cumulative Exergy (UCEx), to the exergy of its inputs (based on the CExD). The Life Cycle Irreversibility Index quantifies technological obsolescence, by comparing UCEx values between real systems and best available technologies (BAT), in order to reveal the inefficiency of a process or a system. For a given exergy-dissipative production system, it is expressed by the ratio between the UCEx indexes of real against theoretical technology processes of functionally equivalent systems, for the same functional unit of output.

Bejan [44] elaborates the "constructal" design (based on a model of branching and cascading resource gradients of circulatory dissipative structures), which predicts general patterns of order in entropy balancing produced across the self-organizing systems scales. The author distinguishes between the types of organization (based on entropy gradients) in nature: The maximum dissipation (Maximum Entropy Production, MEP) of the "inanimate" unconstrained flow systems (large-scale geophysical and other planetary flows), as opposed to the minimum dissipation (Entropy Generation Minimization, EGM) or maximum thermodynamic performance of the "animate" flow systems. The constructal law does not optimize the entropy gradients, but the "access to the currents that flow", determining the evolution of the flow configuration towards a tree architecture characterized by: A fractal-like branching pattern of the space-filling, a size-invariance of the final branch of the network, and a minimization of the energy spent on the resources distribution. The constructal law promotes the "equilibrium flow architecture" concept, a configuration increasing the morphing freedom and flow access. A system's survival depends on its structural capacity to increase compactness (by developing at inner scales), with regard to the evolving flows, and to optimize its territory for movement (spreading across the available space).

Intuitively, emergy is a structural fitness currency, related to structures complexity as storage, while exergy is a functional fitness currency, related to the functional traits (technologies) capacity to build complex (anti-entropic) structures. Emergy is relevant for the resource side and exergy for the consumer side of each of the ecosystem's (biotic) components. Storage should be only transient, in order to preserve the ecosystem freedom degrees (far-from-equilibrium viability), therefore self-organizing mechanisms implement the dissipative capacity as impedance or friction. The unused energy flows are redirected between components via circulatory, constructal flow structures which bifurcate from the spanning cycles linking the sub-systems at the different ecosystem scales and levels of organization (e.g., from biogeochemical cycling to trophic-metabolic chains), in accordance with the principle of maximum empower [11], which states that self-organizing systems maximize the energy flux throughout the network (resources circulation) and are compatible with their environment (implementing their meta-system sustainability rules).

\subsection{Resilience as a Sustainability Orientor}

Holling [45] defines sustainable development as the potential for creating, testing, and maintaining adaptive strategies, thus bridging the concepts of sustainability and resilience. The latter is a self-regulating adaptive mechanism referring to the capacity of a system under disturbance to select viable states by computing adaptive responses. Marchese et al. [46] investigate possible correlations between sustainability and resilience, considering that an integrated perspective would be beneficial in the environmental management context. Both concepts describe the system's survivability and are compatible with the same methodologies, such as life-cycle analysis, but still remain distinct: Sustainability concerns a whole (i.e., a system with its entities and processes), focuses on equilibrium preservation, and applies to larger spatial scales and longer temporal scales, while resilience concerns the processes, focuses on adaption, and selectively applies to the system's temporal or spatial scales. Under unlikely shocks, the systems' responses are regulated by resilience, but under likely pressures they are regulated by sustainability. As a critical function of a system, sustainability is conditioned by the system's resilience. Ecosystems, cultural systems (societies), and SES are complex adaptive systems with emergent properties determined by self-organizing, learning, and adaptive components organically interacting within multi-scale, nested cycling processes. A multi-stable attraction domain offers 
alternate viability solutions (in an evolutionary perspective) for such systems, based on combinations of environmental conditions, resources availability, and configurations of consumer communities. Patterns of exogenous-endogenous attractors combined with control parameters drive the dynamics of complex adaptive systems.

Holling et al. [47] circumscribe the "resilience" concept by identifying three essential features: The function and structure tolerance to perturbations, the self-organizing ability, and the adaptive capacity of structures and processes. The concept's operationalization involves contextualization and management for maintaining the system on sustainable trajectories. Gunderson [48] elaborates on the concept of resilience, introduced in the systems' ecology by C. S. Holling [49] and defined as the ecosystem's capacity to assimilate perturbations without compromising its self-organized processes and structures by leaving its pool of stable states' attractors. Resilience characteristics are: The return time to a stable state, the multiplicity of the stability domain, and the adaptive capacity (to the conditions of a new attraction basin). Provided the group (or ecosystem) level selection and adaptation mechanisms, ecosystems resilience qualifies as a state selector, building cross-scales biodiversity regeneration paths (connected adaptive cycles) from the surviving ecological buffers, in order to preserve the systemic functional responses. Cushman and Mcgariga [50] summarize the concept of ecological resilience: It measures the magnitude of a disturbance able either to radically alter the structure and functions (sets of processes) of an ecosystem or to shift the system's dynamics to a new regime (attraction basin), reflecting the ecosystem's capacity to recover its fundamental structure and processes under the action of stressors. Resilience research observes the species diversity (e.g., in guilds) and functional traits (e.g., in paths degeneracy) involved in the ecosystem maintenance and in stress response, but also investigates the environmental context, patterns, and process interactions. A holistic and multi-scale approach to the ecosystems, using a "panarchy" model of adaptive cycles nested in a hierarchical recursive structure, is necessary for resilience building in restoration and conservation management.

According to Buchholz et al. [51], excessive hierarchical control inhibits SESs' adaptive capacity, but insufficient control inhibits SESs' evolution predictability. Changing factors beyond control requires adaptive management, in the presence of a plurality of natural and social values, perceptions, and objectives. Strong variation in adaptive systems prevents reaching Pareto optimality for both the cultural (social, economic) and ecological agents, forcing perpetual tradeoffs which determine a mostly unpredictable, multi-path evolution towards several optima. As an unfortunate consequence of Odum's maximum empower principle, the economic power concentration by global transformation of regional networks (initially sustainable), which induces scaling-up 'lock in' patterns by positive feedback loops exerting a disproportionate control on the global societal system's evolvability and development, and forcing the cultural selection mechanisms. Walker et al. [52] suggest shifting the sustainability focus, in SESs' dynamics, from optimal states and maximum sustainable yield (the MSY paradigm), towards resilience analysis and adaptive governance. Three related attributes of a SES would determine its future trajectories: Resilience, adaptability, and transformability. Folke [53] suggests modeling SESs' dynamics from a resilience perspective, resulting in adaptive management approaches. The social-ecological resilience is interpreted as the ability to contain disturbance and to remain in the same domain of attraction, due to the SESs self-organization, learning, and adaptation capabilities. The SES concept itself suggests that social and ecological systems are arbitrarily separated. Folke et al. [54] highlight that the ecosystem models are the best source of inspiration for a theoretical framework of sustainability design and management, being centered on life-related concepts as: Autopoietic processes, emergence of attractors, useful (organizational) exergy, working and latent information, nested systems, and holarchy levels.

\subsection{Circularity as a Sustainability Orientor}

Circularity is one of the essential mechanisms supporting the self-sustaining and self-regulating processes in complex adaptive systems. A self-organizing system, such as the ecosystems, has a propensity to balance its internal resources, by simultaneously enclosing processes which can consume 
and produce them. In the natural cycling pathways (such as the trophic chains), perturbations and entropy generation will invariably cascade negative feedbacks, inhibiting processes carried by abiotic, biological, and cultural species (corresponding to the planetary, biosphere and social systems, respectively). Natural and anthropic processes can be lost due to broken thermodynamic, chemical, and biological flows, but are indirectly influenced by cultural circuits of information and causation. Negative feedbacks can be desirable: The system's survival relays on resource processes distribution inhibiting (consuming) and promoting (producing) in space and time, and on their paces optimization. Spontaneous "load balancing" processes are the result of the emergence phenomenon: Each component of a self-regulated system controls its environment, mostly through indirect causation propagating through the network. Indirect actions determine local to global reconfiguration effects due to the system's processes and entities referencing, following a natural resources re-allocation scheme, in order to maintain the overall viability status (network synergism). Adaptive algorithms, computing the "running" processes' priority and pace in function of the resources availability and on the community fitness level, can simulate the nested adaptive cycles of the panarchy model (the multi-scale ecosystem's succession), based on autocatalytic and auto-inhibitory feedback-interrelated processes. This decentralized, co-evolutionary mechanism of mutual control spontaneously manifests throughout the ecosystem's scaling power-laws, regulating the productivity and interactions within the trophic webs of nested communities of organisms, according to a model of heterarchic (mutualistic) rather than hierarchic network. Moreover, such an emergent property is challenged by the Ashby's law of requisite variety: Processes diversity (more freedom degrees) requires higher control, but controlling requires a higher diversity of the control processes. In nature, biotic structures carry most of the control processes and are the fastest evolving vectors. Their trophic and non-trophic interaction chains are regulatory cycles having a dual role of stimulating and inhibiting biodiversity, simultaneously maintaining evolvability and viability degrees throughout the system. Resources circularity implementation, meaning the dynamic control and physical infrastructure required for their balancing, allocation, consumption, and regeneration within the system, denotes a CE. Intuitively, in a closed network, a positive balance between the carrying capacity of all resources and the footprint of all consumers, due to its processes circularization, denotes a sustainable system. For real systems, such a concept requires complex mathematical formalisms and computation algorithms, therefore patterns observed in social-economic systems and in their meta-systems (i.e., the ecosystems) could be useful. Economic value chains (production and consumption systems), a simplified version of the bio-ecological trophic-metabolic chains, are an easily observable and reasonably complex experimental ground, since the energy-material flows derived from inter-agent transactions are finite and can generate computable models. Conversely, bio-ecological networks are probably simpler than social systems, due to the cultural determinism generating, for each transaction, an exponential proliferation of relations, based essentially on information propagation.

Geissdoerfer et al. [55] consider the circular economy as a regenerative system in which resources inputs, waste/emissions outputs and material/energy consumption are "minimized by slowing, closing, and narrowing material and energy loops" by means of long-lasting effect processes like: Design, maintenance, repair, reuse, remanufacturing, refurbishing, and recycling. CE is viewed as a condition for sustainability, a beneficial economic relation, or a trade-off methodology. Kirchherr et al. [56] report a high incidence, in the literature, of the $3 \mathrm{R}$ topics (reduce, reuse, and recycle), without indication for a systemic shift, disconnecting the CE concept from the sustainable development. Social equity, future generations, business models, and life styles-as CE enablers-are left out of scope. The authors suggest representing the $\mathrm{CE}$ as a multi-scale economic system that creates "environmental quality, economic prosperity and social equity", by replacing the end-of-life usual behavior through materials and energy reuse, recycling, and recovery operations in the production, distribution, and consumption processes. Those operations can be driven: At the micro-level by individual systems (e.g., products, organizations, consumers), at the meso-level by symbiotic, finite, and simple systems (e.g., eco-industrial parks), and at the macro-level by complex meta-systems (cities, regions, nations, 
and global structures). Socio-economic cycles can be designed based on: Innovative technologies, business models, and consumers' behavior. Business models should integrate the $3 \mathrm{R}$ framework (reduce, reuse, and recycling) according to a waste hierarchy, and the focus, currently set on economic prosperity, should be placed on curbing down both consumption and economic growth.

According to Korhonen et al. [57] the CE paradigm values, cultures, and societal structures remain unexplored, while the emerging research work on the $\mathrm{CE}$ concept focuses on the computation of the production and consumption systems' material and energy flows. Authors suggest that CE should be practice-oriented and capable to reform production and consumption activities by diffusing new organizational and business models across the industrial system, through innovations in entrepreneurship and technological development. The investigation of Kirchherr et al. [58] reveals that scholar studies relate the slow progress of the CE implementation to the technological barriers, while the concept has still not reached the business mainstream, due to a lack of public policies supporting the circular products market uptake and the simultaneous phase-out of the linear products, but equally due to cultural-behavioral chain reactions. Authors consider CE at an early stage of the technological pathways' implementation. Among the CE challenges identified by Korhonen et al. [59] are mentioned: Governance policies, thermodynamic feasibility, system boundaries, and inter-organizational and inter-sectorial flows management. The authors suggest that value chains, generated from products and services flows derived from natural resources and embedding human work and capital, ideally should include iteration patterns (cycles) maximizing the financial output, while reducing the virgin resources inputs and the emission/waste outputs. Additionally, the CE material and energy flows should be integrated in the natural ecosystem, by adopting a natural model of materially closed flows, fueled by renewable solar energy, with dissipated infrared radiation as the only waste output. In their opinion, $\mathrm{CE}$ has the potential to simultaneously generate sustainable development and quality outputs of higher value, through circular production and consumption systems. A consensus on the CE framework is proposed by Prieto-Sandoval et al. [60], concerning its main components: The demand minimization by resources recirculation, the value recovery from waste and a multilevel societal innovation (evolution). They define the $\mathrm{CE}$ as a change of paradigm regarding the economic system's objectives and the human society's interactions with nature, aiming to prevent the resources depletion by closing energy and material loops, and to implement the sustainable development at all the scales. They identify two classes of actionable instruments for biological and technical resources re-injection in the economic circuit: The $3 \mathrm{R}$ principles (alongside the production, consumption, and resources return cycle) and the environmental design methods. Their application should target: Social-economic innovative business models, cleaner industrial metabolisms, CE solutions' market uptake, and sustainable behaviors (lifestyles).

CE implementation strategies are analyzed by Kalmykova et al. [61], based on case studies. Depending on the used strategies (e.g., stock optimization, eco-efficiency, waste reduction, 4Rs), on the cycling extent (loops magnitude within a value chain) and on the scope (i.e., the scale gradient, from the chemical species to the economic sectors), the authors propose the following classification metadata: Substance, material, product, sector, or system levels, for the scope determination; policy, planning, or vision strategy classes; research and development, knowledge and experience transfer, pilot scale and market ready phases, for the strategies assignment to a technology life cycle stage. Their results show that research is focused on recovery/recycling and consumption/use, but rarely on the supply chain early stages (design), and that implementation levels concern only market-ready solutions, without economic systemic changes. A typology of 10 "value retention options" (ROs) is synthesized by Reike et al. [62], including the 3R (reduce, reuse, recycle) and their short loop variant (redesign, refurbish, repurpose). A hierarchical R-ladder is proposed, as a gradual, multi-stages method for preserving the resources value, based on the IE hierarchies (cascading resources) and model of symbiosis (eco-industrial parks). The value retention concerns an intrinsic value (distinct from the economic value) and refers to a resource's natural state conservation or to the entropy increase prevention along a product's life cycle. The fate of the product is decided by its degree of functional/structural damage: If the function is preserved, the product is considered unaltered, although changes in ownership might occur, 
and it enters short loops (Resell/Reuse, Reduce, Refuse); if the function is upgraded by reprocessing, the product enters medium long loops (Remanufacture, Refurbish, Repair); if the function loss is substantial and only allows a down-cycling, the product enters long loops (Re-mine, Recover, Recycle, Repurpose/Rethink). RO's do not formalize neither biological flows (although an abstract formalism based on common patterns could be developed) nor services life cycle (which combine material, energy and information flows, also needing higher abstraction level for a conceptual homogenization) and do not prioritize functionality-driven business models (currently relaying essentially on mutualism or competition patterns) and entropy reduction (by design). In denial of the self-centered business logic of the "healthy growth", the system thinking promotes processes based on low resources inputs (i.e., Refusing and Reducing ROs) and suggests to reconsider not only the production, distribution, and consumption processes, but also the property rights (excessive buffering prevents flows circulation and causes processes extinction). Influential think-tanks, like the Ellen MacArthur Foundation, suggest a gradual shift and a decoupling from the production growth, while the $\mathrm{CE}$ projections issuing from global structures (like EU, OECD, and WEF) are still related to a competitive economic growth and remain oriented towards the resource efficiency (instead of eco-effectiveness and cradle-to-cradle production cycles).

The CE concept's operationalization depends on its metrics' objectivity. The Ellen MacArthur Foundation [63] identifies two types of cycles with economic applications: Biological (non-toxic materials recovery within the biosphere, after their cascaded use as resources) and technical (components recovery via the market). The Materials Circularity Index (MCI) considers only the technical cycle: Raw materials and components from reuse and recycling, life cycle prolongation and intensive use by performance improving. The index is a combination of circular (restoring by recycling and reusing) and linear (consuming to waste and waste energy) parts of the flows. In the end-of-life strategies, the shorter, more technical and more closed the cycles, the higher the extractible economic value. For instance, reusing maintains the product's incorporated energy and complexity, by contrast with recycling, where only basic elements are recoverable. The MCI methodology defends a CE theory based on the design of more circular business models for the products' value maximization and retention along their life cycle. Pauliuk [64] exposes the CE-related standard "BS 8001:2017-Framework for implementing the principles of the CE in organizations", which proposes a reconciliation between business routines and CE principles, strategies, and implementation, but still omits monitoring. The author suggests quantitative indicators for a CE scorecard based on: General systems definitions, material flow analysis (MFA), and life cycle assessment (LCA). The core indicators are: The service lifetime (of a material in the techno-sphere) and the in-use stock growth. The author highlights that $\mathrm{CE}$ strategies should be monitored from a common systems perspective, avoiding incoherent, corporate-specific indicators in conflict with the CE sustainability goals.

Nayha [65] mentions that CE originates from environmental economics and IE as an umbrella concept concentrating different resources conservation strategies in a framework defined by The Ellen MacArthur Foundation as "restorative and regenerative by design". CE's purpose is to dissociate economic growth and resource consumption, possibly by de-growth strategies. Business model innovations are a key for $\mathrm{CE}$ and sustainability, but the business community links CE to established practices and to technological models, rejecting fundamental mutations. CE should not be seen as automatically sustainable: Tools like LCAs may contribute to its evaluation. Gontard et al. [66] observe that a systemic IE vision within the CE functional space is required to generate eco-innovative business models bringing together: The life cycle thinking, a territorial material flow analysis and catalyzing techniques based on local feedback loops. Yoon et al. [67] suggest inducing CE patterns (resource-based cross-processes feedbacks) with the IE framework application to the design of mid-scale business models, targeting the environmental impacts reduction and higher resources efficiency. By replacing the linear processes with industrial symbiosis closed loops, an IE holistic approach improves the cluster's environmental response. 


\section{Towards an Ecosystem Model for Sustainability}

Abandoning the artificial separation of the ecological, economic, and social dimensions of the SESs' sustainability in favor of a homogenized modeling approach requires abstracting the various types of agents to the level of the last common ancestor who can eliminate a conceptual barrier (e.g., ecological and social systems separation in SESs, ecological compartmentalization, system boundary setting in LCA) by relaying indirect causal effects of a transaction throughout the network (a consequential approach). The ultimate abstract ancestors will be the molecular species in a reactor. When the reactor is an ecosystem, intra-species and inter-species interactions will generate behavioral patterns. In consumptive reactions (trophic interactions or transactions), an entity (individual or group, but considered from an atomistic perspective) of a molecular species can alternately act as resource or consumer, related to the other reactive entities of the same or different molecular species. In complex reactions, involving more than a resource and a consumer (individuals or species), molecular species (e.g., organisms, economic entities) can compete for the same resource. Competition for resources generates constraints which determine adaptive transformations within the network (mediated by feedbacks), such as reactions diversification, consumers specialization, or resources evolution (e.g., developing defensive functional traits or behaviors). A holistic view on the transformations in an ecosystem simulates a teleological, goal-driven dynamics. Therefore, self-organization processes in ecosystem models can be represented as goal functions [33]. This model of an ecosystem evolving towards (or selecting) states which optimize global properties would be a conceptual representation of ecological communities' dynamics maximizing goal functions at the group level and it would neither extrapolate the natural selection theory nor invoke the Gaia hypothesis, the optimized goal functions (orientors) at the system level being of a different nature than the individual biological fitness.

The ultimate purpose of a homogenous conceptual and abstract representation of the biological and cultural communities would be to obtain a repository of generic patterns (for behaviors and interactions) applicable to various contexts. Reaction rules could be synthesized from these patterns and added to the studied network, in order to extend or reduce the SES's assemblage to a self-organized community. Such a "total ecosystem", tending to the "organization" concept, would approximate the COT's theoretical model of sustainability, based on an adaptive algorithm for constructing the hierarchy of organizations. The "total ecosystem" should be composed of necessary and sufficient reactive biological and cultural species, with only their stoichiometric and kinetic patterns useful for predicting sustainable scenarios throughout the network. Cultural species can be defined based on their activity or social function (e.g., profession) and assigned to biological species. Intuitively, "naturalness" defines sustainable scenarios, but neither can be estimated with precision nor can qualify as an absolute reference for a persistent and autonomous system. Therefore, sustainability needs to be matched against a theoretical model. Stoichiometry (concentrations) and kinetic rates drive the metabolic flows (transactions) throughout the trophic webs, which are relatively invariant (slow changing) patterning structures in the system's network. Trophic webs are made by connected trophic chains built on reactive compatibilities (chemical, bio-physical, cultural). In an ecosystem's sustainability model, orientors regulate the species' processes connectance, tending to optimize resources distribution and to limit their consumption, by applying trophic gradients and constraints. Thermodynamic orientors, at higher levels of the orientors' hierarchy, optimize the energy distribution and minimize the local entropy, generating self-organization patterns. Some of the candidate thermodynamic orientor-based indicators are the emergy-exergy ratio, the technology obsolescence ratio, and the exergy loss and entransy dissipation rates in constructal flow structures. The same orientors apply to the technosphere gradients, as a common conceptual substrate for ecological interactions (driven by a biological causation) and social-economic interactions (driven by a cultural causation), enabling not only comparisons, but also a unified formalism able to implement the SESs transitive closure between biological and cultural (social-economic) species and to bring their assigned processes to a canonical form. Abstracted to a common level, the biological and cultural determinisms also shape dynamic (behavioral) patterns, resulting from either non-trophic (e.g., competition, antagonism, amensalism, 
neutralism, commensalism, mutualism) or trophic (e.g., predation, symbiosis) interactions between biological and cultural species.

The components of the system can be unstable and their interactions irregular, making the system vulnerable to external attractors or to internal repellors (e.g., migratory flows), or they can show a meta-stability due to the system's internal attractors, coevolve, and form functional groups (e.g., division of labor, specialization, and guilds), based on functional patterns. Functional speciation is one of the fundamental self-organizational patterns of sustainability in a system with mutually adapting and co-evolving components. Modeling the "evolution" of a system combines extremal principles characterizing its levels of organization and operating with orientors corresponding to thermodynamic, chemical, biological, and cultural determinisms. By creating functional groups of components, the system maximizes positive mutual effects (network synergism) and increases its organizational degree (e.g., dynamic patterns), while continuously changing and preserving a sufficiently high number of degrees of freedom (freedom to morph or evolvability). Patterns can configure the complex systems of coupled populations of species: Probability densities (in the states space) will tend to harmonic oscillators and the relative probabilities ratios will be bound, stabilizing the system's internal kinetics in "far from equilibrium" regimes and maintaining its "elastic" resilience. Meta-stability emerging from the chaotic mutual dynamics of a high number of components could be approached more effectively by problem partitioning (than by stochastic and mechanistic models generating costly computing algorithms), which reduces the number of system's degrees of freedom (dimensionality). To this purpose, the identification and factorization of dynamic patterns is necessary, and this is the rationale for developing a new kind of model for sustainability evaluation in SESs management. Patterns determine regularity regimes (e.g., quasi-periodic dynamics or spatial configurations based on symmetries, like the multi-fractal self-similarity configuring the hierarchy of niches and their occupation by speciation, in multi-scale ecosystems), constraining the system's dynamics to a finite number of states space partitions (phases). Sustainability modeling requires a theoretical basis unifying extremal principles and constraints generative of recursive patterns, issued from the systems' thermodynamic, chemical, biological, and cultural determinisms, at several nested abstraction levels, according to an object-oriented architecture. COT could be the modeling language for the highest abstraction levels, and the ecological models could implement the intermediate abstraction layer of the concepts. A hierarchy of sustainability orientors could be designed, following generality-specificity gradients (e.g., biological speciation or cultural specialization) and considering the degree of influence of the interfering "causal fields" (the four above-mentioned types of determinisms), in order to characterize the self-organization capability of SESs. Resilience and circularity (CE), as markers of the system's emergence, might be considered the highest self-organization level of orientors (Figure 2).

Ostrom [68] suggests a generic conceptual model for representing the interactions of systems linked by social, economic, and political settings with related ecosystems. The model relays on a multi-level nested framework of relationships among four first-level core subsystems: Resource, resource units, governance, and user. The author concludes that long-term sustainability depends on the rules compatibility with the attributes and the self-organization of the resource, resource units, and users systems. In SES' sustainability management, institutions should exert control on the density of species populations in natural ecosystems and on their dispersal only for preserving the ecosystems' self-organization mechanisms. According to Odum [11], self-organizing systems develop without external control. In exchange, policies should focus on ecological-based ratios of resource gradients (e.g., emergy or intrinsic value) versus consumer gradients (e.g., exergy or technology effectiveness), specific to each anthropic entity type, evaluating also its contribution to the system's self-organization, in particular to the optimization of circularity, resilience, evolvability (e.g., functional traits adaptations, specific exergy increase), and redundancy. The integration of the duality consumer-resource in the anthropic network connections seeks for an extension of the principle of footprint limiting through the principle of limiting the influence over the social-ecological network for a balanced control, which is the equivalent of better flowing energy, matter, and information, without buffering more 
than necessary, by implementing circular and constructal (circulatory) extremal principles. Such a management strategy would implement the functionalization throughout the "total ecosystem", via a multi-scale mapping of the anthropic entities' populations to the available niches, in accordance with ecological models of functional traits and biomass distribution power-laws. The current cultural models strongly inhibit the network synergism, by encouraging the individual cultural fitness via a maximum concentration of economic power, disconnecting the anthropic cultural orientors from higher level ecological orientors assigned to biological, chemical, and thermodynamic determinisms, which causes diversity loss, pollution, and climate change, respectively. Eventually, the concept of species encloses a series of assigned endogenous and exogenous processes carried by each phenotype and defining its multilevel and multi-scale interactions. Therefore, considered the functionalization level of the ecosystem's components, local biodiversity loss effects (cumulated at the biosphere scale) are significant, causing progressive suppression of ecosystem functions and noxious, deep, fast, and irreversible reconfigurations of the ecosphere. Consequently, SESs sustainability management could benefit from a "total ecosystem" model implementing self-organization mechanisms: Heterarchical control (distributed and participative instead of centralized and hierarchic control), ecological functions natural and dynamic hierarchies for prioritization of the processes influence throughout the (reactions) network and a dual perspective on entities (as "reaction vessels" ultimately consisting of phenotypes of biological and cultural species), which carry, simultaneously, resource and consumer processes, linking the processes and flowing matter, energy, and information. The two-sided structure of an entity ideally seeks for balancing its own conservation goals and the evolutionary pressures exerted by the system.

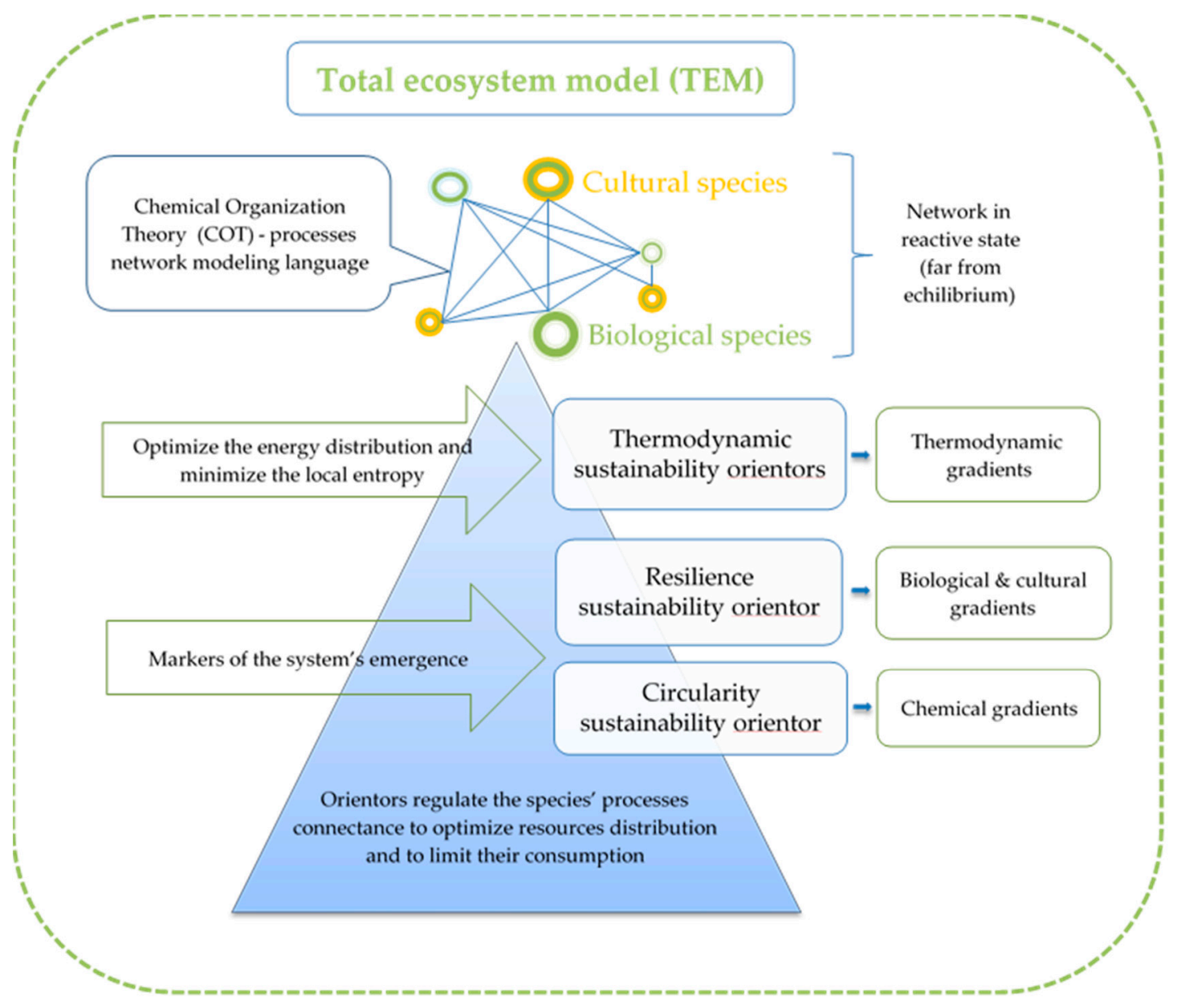

Figure 2. Total ecosystem model. 
LCA is a reference framework for assessing the impacts and even for managing the sustainability of the production systems. Life cycle inventory analysis (LCI), using mass and economic value as allocation criteria of material-energy flows and a system boundary determination based on conventional methods (e.g., additive system expansion or allocation by: Substitution, cut-off, 50/50, closed loop, or loss of quality methods), although useful for liabilities attribution, remains only a conventional accountancy methodology, which is not suitable for sustainability evaluation in the context of the transactional and relational complexity of ecological networks. Moreover, the results of a life cycle impact assessment (LCIA) depend on a variety of disparate causal assumptions, eventually being aggregated based on arbitrary weighting, and models which cannot compute or even conceptually represent complex determinisms. A major inconvenient of the LCIA concerns the evaluation of the anthropic production and consumption systems' direct and indirect effects on the local biodiversity, due to its limited scope. For instance, Crenna et al. [69] observe that wood, in spite of being a valuable resource for industrial and domestic processes, is considered by the various methods of LCIA without addressing the basic information concerning the originating tree species and their habitat, dispersal patterns, vulnerability or source ecosystem type (natural or managed). Authors highlight the necessity of focusing on: The species distribution and ecological status, the re-definition of the ecosphere-technosphere separatrix, the identification of impact pathways for both the harvested resource and ecosystem health, and the definition of a renewability indicator for natural biotic resources. However, they base their proposed assessment framework on the species' commercial value (anthropic exchange currency), with no signification for the wood species' fitness. Instead, in particular when modeling and evaluating sustainability, objective and inter-specific valuation criteria would be more appropriate, based on homogenous exchange currencies having a regulatory effect over the entire SES and influencing its degree of emergence and self-organization. When extrapolated (beyond their native type of reactions network, with its organizational principles), low-level currencies (e.g., monetary value) inhibit the meta-system transition towards a higher-level organization (in the COT sense) and implicitly, the sustainability pathways.

In its conceptual phase, the total ecosystem model challenges some of the assumptions derived from classical sustainability approaches, concerning topics such as: Aggregation and scaling, limiting factors, tipping points, tradeoffs between agents, basic orientation in ecosystems, and system-environment material-energy flows exchange. The model construction articulates some major results of recent multi-disciplinary research topics, such as: Reactions networks, biological relativity, renormalization groups, within an architecture which combines systems ecology's concepts and object-oriented abstract modeling. In return, testing the model will provide feedbacks to these relatively young research fields, besides advancing or at least enriching the SESs' sustainability conceptualization and management.

\section{Conclusions}

The sustainability related concepts and models reached a certain maturity and offer the opportunity for setting a sound theoretical ground for reconciliation and operationalization. Some of the major methods and tools (e.g., CBS/MCS, essential capitals, LCA) subscribe to the TBL framework, which dominates the theoretical landscape, while others belong to the ecological footprint family (e.g., the SPI). Concepts like resilience and circularity became influential, and the literature confirms their closeness degree to the core sustainability conceptualization, although originating from different perspectives (theoretical ecology versus economy). Theoretical ecology joins the orientation theory of viable and sustainable systems, providing a conceptual model based on self-organization gradients or goal functions (e.g., fitness functions, thermodynamic orientors). The COT defines the "organization" concept and a reaction networks language which can provide a higher abstraction level for ecological and socio-economic processes and entities, a formalism for sustainability orientors (and their computation) and the algorithms for generic and specific sustainability patterns identification in a reactions network. The sustainability problematization revealed the motifs of a possible model of ecological networks inspiration, the "total ecosystem", which immerses the anthropic cultural (social-economic) 
system in a web of cascading relations between entities (represented as processes sources and sinks) of biological or cultural species, being constrained by thermodynamic, chemical, biological, and cultural gradients. The total ecosystems' sustainable reactive states are essentially determined by the mutual regulation between these four gradient types and the three categories of ecological extremal principles: Resilience (linked to biological and cultural gradients), circularity (linked to chemical gradients), and thermodynamic orientors (linked to energy gradients). Future developments of the total ecosystem model concern the completion of operational deployment sequences producing outcomes easy to use by the SESs' management research and practice, such as the computation of sustainable regimes by changing values of the system's parameters.

The total ecosystem model can be a useful tool for providing the necessary elements to maintain/improve the sustainability status of an ecosystem under perturbations. The model will comprise the ecological system (e.g., soil ecosystems, landscape ecosystems) and the SES (production systems, local communities, markets) and will implement a co-evolutionary unified perspective of the resulting social-ecological system. Such a model will formalize interactions between a system's components, based on an abstraction level capable of identifying the causal links throughout the system and to capture the consequent fitness and sustainability dynamics of the system.

The model is intended for researchers and users concerned with analytical and decisional activities regarding the regulation of SESs. Consequently, the outcome has to enable the simultaneous control of the ecological, economic, and social fitness compatibility with the sustainability criteria, by inter-playing the appropriate constraints in order to preserve the system's viability. The main requirement of such an analytical and decisional instrument will be to correctly define necessary and sufficient concepts (interacting entities, their causal relationships, and their regulating strategies) as well as the focal system's viable states.

Author Contributions: Conceptualization, methodology, and writing, E.K.; investigation, M.-A.H., L.S., and D.A.S.; review and validation, D.E.D., supervision C.R. All authors have read and agreed to the published version of the manuscript.

Funding: This research was founded by a grant of the Romanian Ministry of Research and Innovation, CCCDI-UEFISCDI, project number PN-III-P1-1.2-PCCDI-2017 0251/4PCCDI/2018, and by the Romanian Research and Innovation Ministry under the PROINSTITUTIO project, contract no. 19PFE/17.10.2018.

Conflicts of Interest: The authors declare no conflict of interest. The funders had no role in the design of the study; in the collection, analyses, or interpretation of data; in the writing of the manuscript, or in the decision to publish the results.

\section{References}

1. Harrington, L.M.B. Sustainability theory and conceptual considerations: A review of key ideas for sustainability, and the rural context. Pap. Appl. Geogr. 2016, 2, 365-382. [CrossRef]

2. Geissdoerfer, M.; Bocken, N.; Hultink, E.J. Design thinking to enhance the sustainable business modelling process-A workshop based on a value mapping process. J. Clean. Prod. 2016, 135, 1218-1232. [CrossRef]

3. Pollesch, N.L.; Dale, V.H. Normalization in sustainability assessment: Methods and implications. Ecol. Econ. 2016, 130, 195-208. [CrossRef]

4. Salas-Zapata, W.A.; Ortiz-Muñoz, S.M. Analysis of meanings of the concept of sustainability. Sustain. Dev. 2018, 27, 153-161. [CrossRef]

5. Buchholz, T.; Luzadis, V.A.; Volk, T.A. Sustainability criteria for bioenergy systems: Results from an expert survey. J. Clean. Prod. 2009, 17, 586-598. [CrossRef]

6. Fath, B.D. Systems ecology, energy networks, and a path to sustainability. Int. J. Des. Nat. Ecodynamics 2017, 12, 1-15. [CrossRef]

7. Levin, S.; Xepapadeas, T.; Crépin, A.-S.; Norberg, J.; Zeeuw, A.; Folke, C.; Hughes, T.; Kenneth, A.; Barrett, S.; Daily, G.; et al. Social-ecological systems as complex adaptive systems: Modeling and policy implications. Environ. Dev. Econ. 2013, 18, 111-132. [CrossRef] 
8. Guarini, M.R.; Morano, P.; Sica, F. Eco-system Services and Integrated Urban Planning. A Multi-criteria Assessment Framework for Ecosystem Urban Forestry Projects. In Values and Functions for Future Cities; Mondini, G., Oppio, A., Stanghellini, S., Bottero, M., Abastante, F., Eds.; Springer International Publishing: Cham, Switzerland, 2020; pp. 201-216.

9. Lin, Y.; Sutherland, W.J. Compartmentalization influences the response of bioenergetic ecological networks to species declines. J. Complex Netw. 2015, 4, 140-155. [CrossRef]

10. Fath, B.D.; Scharler, U.M.; Ulanowicz, R.E.; Hannone, B. Ecological network analysis: Network construction. Ecol. Model. 2007, 208, 49-55. [CrossRef]

11. Odum, H.T. Environmental Accounting: Emergy and Environmental Decision Making; John Wiley and Sons: New York, NY, USA, 1996.

12. Milne, J.M.; Gray, R. W(h)ither Ecology? The Triple Bottom Line, the Global Reporting Initiative, and Corporate Sustainability Reporting. J. Bus. Ethics 2013, 118, 13-29. [CrossRef]

13. Sala, S.; Ciuffo, B.; Nijkamp, P. A systemic framework for sustainability assessment. Ecol. Econ. 2015, 119, 314-325. [CrossRef]

14. Waring, T.M.; Kline, M.A.; Brooks, J.S.; Goff, S.H.; Gowdy, J.; Janssen, M.A.; Smaldino, P.E.; Jacquet, J. A multilevel evolutionary framework for sustainability analysis. Ecol. Soc. 2015, 20, 34. [CrossRef]

15. Fath, B.D. Quantifying economic and ecological sustainability. Ocean Coast. Manag. 2015, 108, 13-19. [CrossRef]

16. Alvesson, M.; Sandberg, J. Generating research questions through problematization. Acad. Manag. Rev. 2011, 36, 247-271.

17. Weder, F.; Tungarat, A.; Lemke, S. Sustainability as Cognitive "Friction": A Narrative Approach to Understand the Moral Dissonance of Sustainability and Harmonization Strategies. Front. Commun. 2020, 5. [CrossRef]

18. Van de Kerk, G.; Manuel, A.R. A comprehensive index for a sustainable society: The SSI-The Sustainable Society Index. Ecol. Econ. 2008, 66, 228-242. [CrossRef]

19. McElroy, M.W.; Thomas, M.O. The MultiCapital Scorecard. Sustain. Account. Manag. Policy J. 2015, 6, $425-438$.

20. Bossel, H. Assessing Viability and Sustainability: A Systems based Approach for Deriving Comprehensive Indicator Sets. Conserv. Ecol. 2001, 5, 12. [CrossRef]

21. Wackernagel, M.; Schulz, N.B.; Deumling, D.; Linares, A.C.; Jenkins, M.; Kapos, V.; Monfreda, C.; Loh, J.; Myers, N.; Norgaard, R.; et al. Tracking the ecological overshoot of the human economy. Proc. Natl. Acad. Sci. USA 2002, 99, 9266-9271. [CrossRef]

22. Wackernagel, M.; Galli, A.; Hanscom, L.; Lin, D.; Mailhes, L.; Drummond, T. Ecological Footprint Accounts: Principles 1. In Routledge Handbook of Sustainability Indicators, 1st ed.; Bell, S., Morse, S., Eds.; Routledge: London, UK, 2018; pp. 244-264.

23. Krotscheck, C.; Narodoslawsky, M. The Sustainable Process Index a new dimension in ecological evaluation. Ecol. Eng. 1996, 6, 241-258. [CrossRef]

24. Narodoslawsky, M. Sustainable process index. In Assessing and Measuring Environmental Impact and Sustainability; Klemeš, J.J., Ed.; Butterworth-Heinemann: Oxford, UK, 2015; pp. 73-86.

25. Bossel, H. Goal Functions and Orientors. In Encyclopedia of Ecology, 2nd ed.; Fath, B.D., Ed.; Elsevier: Oxford, UK, 2008; pp. 598-605.

26. Ehrenfeld, J.R. Industrial ecology: A new field or only a metaphor? J. Clean. Prod. 2004, 12, 825-831. [CrossRef]

27. Lifset, R.; Graedel, T.E. Industrial Ecology. In International Encyclopedia of the Social E Behavioral Sciences, 2nd ed.; Wright, J.D., Ed.; Elsevier: Oxford, UK, 2015; pp. 843-853.

28. Pauliuk, S.; Hertwich, E.G. Socioeconomic metabolism as paradigm for studying the biophysical basis of human societies. Ecol. Econ. 2015, 119, 83-93. [CrossRef]

29. Ekener, E.; Hansson, J.; Larsson, A.; Peck, P. Developing Life Cycle Sustainability Assessment methodology by applying values-based sustainability weighting-Tested on biomass based and fossil transportation fuels. J. Clean. Prod. 2018, 181, 337-351. [CrossRef]

30. Millward-Hopkins, J.; Busch, J.; Purnell, P.; Zwirner, O. Fully Integrated Modelling for Sustainability Assessment of Resource Recovery from Waste. Sci. Total Environ. 2018, 612, 613-624. [CrossRef] [PubMed]

31. Schiller, F.; Penn, A.S.; Basson, L. Analyzing networks in industrial ecology-A review of Social-Material Network Analyses. J. Clean. Prod. 2014, 76, 1-11. [CrossRef]

32. Patten, B.C. Network Orientors: Steps Towards a Cosmography of Ecosystems: Orientors for Directional Development, Self-Organization, and Autoevolution. In Eco Targets, Goal Functions, and Orientors; Muller, F., Leupelt, M., Eds.; Springer: Berlin/Heidelberg, Germany, 1998; pp. 137-160. 
33. Jorgensen, S.E.; Nielsen, S.N. Thermodynamic Orientors: A Review of Goal Functions and Ecosystem Indicators. In Eco Targets, Goal Functions, and Orientors; Muller, F., Leupelt, M., Eds.; Springer: Berlin/Heidelberg, Germany, 1998; pp. 123-136.

34. Alberti, M.; Marzluff, J.M.; Shulenberger, E.; Bradley, G.; Ryan, C.; Zumbrunnen, C. Integrating Humans into Ecology: Opportunities and Challenges for Studying Urban Ecosystems. BioScience 2003, 53, 1169-1179. [CrossRef]

35. Heylighen, F.; Beiggi, S.; Veloz, T. Chemical Organization Theory as a Modeling Framework for Self-Organization, Autopoiesis and Resilience. ECCO Working Papers 2015-01. Available online: http://pespmc1.vub.ac.be/Papers/COT-ApplicationSurvey.pdf (accessed on 22 September 2020).

36. Veloz, T.; Razeto-Barry, P. Reaction Networks as a Language for Systemic Modeling: Fundamentals and Examples. Systems 2017, 5, 11. [CrossRef]

37. Veloz, T. The Complexity-Stability Debate, Chemical Organization Theory, and the Identification of Non-classical Structures in Ecology. Found. Sci. 2020, 25, 259-273. [CrossRef]

38. Matsumaru, N.; Centler, F.; Dittrich, P. Chemical Organization Theory as a Theoretical Base for Chemical Computing. In Workshop on Unconventional Computing; Teuscher, C., Adamtzky, A., Eds.; Luniver Press: Beckington, UK, 2005; pp. 71-83.

39. Nielsen, S.N.; Jorgensen, S.E. Goal functions, orientors and indicators (GoFOrIt's) in ecology. Application and functional aspects—Strengths and weaknesses. Ecol. Indic. 2013, 28, 31-47. [CrossRef]

40. Brown, M.T.; Ulgiati, S. Emergy Evaluation of the Biosphere and Natural Capital. AMBIO 1999, $28,486-493$.

41. Bastianoni, S. Use of Thermodynamic Orientors to Assess the Efficiency of Ecosystems: A case study in the Lagoon of Venice. Sci. World J. 2002, 2, 255-260. [CrossRef] [PubMed]

42. Zvolinschi, A.; Kjelstrup, S.; Bolland, O.; Van der Kooi, H.J. Exergy Sustainability Indicators as a Tool in Industrial Ecology. J. Ind. Ecol. 2007, 11, 85-98. [CrossRef]

43. Gulotta, T.M.; Guarino, F.; Mistretta, M.; Cellura, M.; Lorenzini, G. Introducing exergy analysis in life cycle assessment: A case study. Math. Model. Eng. Probl. 2018, 5, 139-145. [CrossRef]

44. Bejan, A. Constructal theory of pattern formation. Hydrol. Earth Syst. Sci. 2007, 11, 753-768. [CrossRef]

45. Holling, C.S. Understanding the Complexity of Economic, Ecological, and Social Systems. Ecosystems 2001, 4, 390-405. [CrossRef]

46. Marchese, D.; Reynolds, E.; Bates, M.E.; Morgan, H.; Clark, S.S.; Linkov, I. Resilience and sustainability: Similarities and differences in environmental management applications. Sci. Total Environ. 2018, 613, 1275-1283. [CrossRef]

47. Holling, C.S.; Walker, B. Resilience Defined. 2003. Available online: http://isecoeco.org/pdf/resilience.pdf (accessed on 24 September 2020).

48. Gunderson, L.H. Ecological Resilience-In Theory and Application. Annu. Rev. Ecol. Syst. 2000, 31, 425-439. [CrossRef]

49. Holling, C.S. Resilience and Stability of Ecological Systems. Annu. Rev. Ecol. Syst. 1973, 4, 1-23. [CrossRef]

50. Cushman, S.A.; Mcgariga, K. Metrics and Models for Quantifying Ecological Resilience at Landscape Scales. Front. Ecol. Evol. 2019, 7, 440. [CrossRef]

51. Buchholz, T.; Volk, T.A.; Luzadis, V. A participatory systems approach to modeling social, economic and ecological components of bioenergy. Energy Policy 2007, 35, 6084-6094. [CrossRef]

52. Walker, B.; Holling, C.S.; Carpenter, S.R.; Kinzig, A. Resilience, adaptability and transformability in social-ecological systems. Ecol. Soc. 2004, 9, 5. [CrossRef]

53. Folke, C. Resilience: The emergence of a perspective for social-ecological systems analysis. Glob. Environ. Chang. 2006, 16, 253-267. [CrossRef]

54. Folke, G.; Folke, C. Characteristics of nested living systems. J. Biol. Syst. 1993, 1, 257-274.

55. Geissdoerfer, M.; Savaget, P.; Bocken, N.M.P.; Hultink, E.J. The circular economy-A new sustainability paradigm? J. Clean. Prod. 2017, 143, 757-768. [CrossRef]

56. Kirchherr, J.; Reike, D.; Hekkert, M. Conceptualizing the circular economy: An analysis of 114 definitions. Resour. Conserv. Recycl. 2017, 127, 221-232. [CrossRef]

57. Korhonen, J.; Nuur, C.; Feldmann, A.; Birkie, S.E. Circular economy as an essentially contested concept. J. Clean. Prod. 2018, 175, 544-552. [CrossRef]

58. Kirchherr, J.; Piscicelli, L.; Bour, R.; Kostense-Smit, E.; Muller, J.; Huibrechtse-Truijens, A.; Hekkert, M. Barriers to the Circular Economy: Evidence from the European Union (EU). Ecol. Econ. 2018, 150, 264-272. [CrossRef] 
59. Korhonen, J.; Honkasalo, A.; Seppala, J. Circular Economy: The Concept and its Limitations. Ecol. Econ. 2018, 143, 37-46. [CrossRef]

60. Prieto-Sandoval, V.; Jaca, C.; Ormazabal, M. Towards a consensus on the circular economy. J. Clean. Prod. 2018, 179, 605-615. [CrossRef]

61. Kalmykoava, Y.; Sadagopan, M.; Rosado, L. Circular economy-From review of theories and practices to development of implementation tools. Resour. Conserv. Recycl. 2018, 135, 190-201. [CrossRef]

62. Reike, D.; Vermeulen, W.J.V.; Witjes, S. The circular economy: New or Refurbished as CE 3.0?-Exploring Controversies in the Conceptualization of the Circular Economy through a Focus on History and Resource Value Retention Options. Resour. Conserv. Recycl. 2018, 135, 246-264. [CrossRef]

63. Ellen MacArthur Foundation. Towards the Circular Economy-Economic and Business Rationale for an Accelerated Transition. 2013. Available online: https://www.ellenmacarthurfoundation.org/ assets/downloads/publications/Ellen-MacArthur-Foundation-Towards-the-Circular-Economy-vol.1.pdf (accessed on 29 September 2020).

64. Pauliuk, S. Critical appraisal of the circular economy standard BS 8001:2017 and a dashboard of quantitative system indicators for its implementation in organizations. Resour. Conserv. Recycl. 2018, 129, 81-92. [CrossRef]

65. Nayha, A. Transition in the Finnish forest-based sector: Company perspectives on the bioeconomy, circular economy and sustainability. J. Clean. Prod. 2019, 209, 1294-1306. [CrossRef]

66. Gontard, N.; Sonesson, U.; Birkved, M.; Mejone, M.; Bolzonella, D.; Celli, A.; Angellier-Coussy, H.; Jang, Q.W.; Verniquet, A.; Broeze, J.; et al. A research challenge vision regarding management of agricultural waste in a circular bio-based economy, Critical Reviews. Environ. Sci. Technol. 2018, 48, 614-654. [CrossRef]

67. Yoon, S.; Nadvi, K. Industrial clusters and industrial ecology: Building 'ecocollective efficiency' in a South Korean cluster. Geoforum 2018, 90, 159-173. [CrossRef]

68. Ostrom, E. A General Framework for Analyzing Sustainability of Social-Ecological Systems. Science 2009, 325, 419-422. [CrossRef]

69. Crenna, E.; Sozzo, S.; Sala, S. Natural biotic resources in LCA: Towards an impact assessment model for sustainable supply chain management. J. Clean. Prod. 2018, 172, 3669-3684. [CrossRef]

Publisher's Note: MDPI stays neutral with regard to jurisdictional claims in published maps and institutional affiliations.

(C) 2020 by the authors. Licensee MDPI, Basel, Switzerland. This article is an open access article distributed under the terms and conditions of the Creative Commons Attribution (CC BY) license (http://creativecommons.org/licenses/by/4.0/). 